\title{
The prognostic significance of fibroblast growth factor receptor 4 in non-small-cell lung cancer
}

This article was published in the following Dove Press journal:

OncoTargets and Therapy

22 May 2015

Number of times this article has been viewed

\section{Hong-ping Huang \\ Hui Feng \\ Hong-bo Qiao \\ Ze-xiang Ren \\ Ge-dong Zhu}

Department of General Medicine, Linyi Hospital Affiliated to

Shandong University, Linyi City,

People's Republic of China
Correspondence: Hong-ping Huang Department of General Medicine, Linyi Hospital Affiliated to Shandong University, 233\#, East of Phoenix Street, Hedong District, Linyi City, 276034 Shandong Province, People's Republic of China

Tel +86 I87 531301 I 4

Fax +865398222186

Email easonlinyi@163.com
Background: Fibroblast growth factor receptor 4 (FGFR4) has been proved to be correlated with progression and prognosis in many cancers. However, the significance of FGFR4 in nonsmall-cell lung cancer (NSCLC) is still not well elucidated.

Methods: In our experiment, we detected FGFR4 expression in 237 samples of NSCLC with immunohistochemistry, and further analyzed the correlation between FGFR4 and clinicopathologic features of NSCLC with chi-square test. Moreover, we evaluated the prognostic value of FGFR4 by Kaplan-Meier survival curve and Cox regression model. By regulating the expression of FGFR4 by overexpression or knockdown, we assessed the role of FGFR4 on NSCLC cell proliferation.

Results: FGFR4 expression was high in NSCLC (46.8\%, 111/237). FGFR4 expression was significantly associated with tumor diameter $(P=0.039)$. With univariate $(P=0.009)$ and multivariate $(P=0.002)$ analysis, FGFR4 was identified as an independent prognostic factor in NSCLC $(P=0.009)$. Moreover, FGFR4 can promote the proliferation of NSCLC cell lines.

Conclusion: FGFR4 is an independent prognostic biomarker in NSCLC. FGFR4 can accelerate the proliferation of NSCLC cell lines, indicating FGFR4 could be a potential drug target of NSCLC.

Keywords: fibroblast growth factor 4, non-small-cell lung cancer, prognosis, proliferation

\section{Introduction}

Lung cancer is the most frequent cancer type, which leads to the most cases of cancerrelated mortality in the world. ${ }^{1}$ The mortality and morbidity of lung cancer is still rising worldwide, especially in developing countries, partly because of the air pollution. ${ }^{2}$ Based on the clinical and histologic proof, lung cancer can be divided into small-cell lung cancer and non-small-cell lung cancer (NSCLC). NSCLC accounts for $85 \%$ of the primary bronchogenic carcinomas and has the highest mortality rate of malignant tumors in the world. ${ }^{3}$ NSCLC was traditionally considered as a single entity, with tumor stage regarded as the primary factor determining proper treatment. However, NSCLC consists of multiple and diverse histologic types and subtypes, with adenocarcinoma and squamous cell lung cancer. The molecular carcinogenesis of NSCLC features with multiple alterations of gene expression, which result in ectopic signaling pathways and biological behaviors. ${ }^{4-6}$ Although several biomarkers have been proved to be related with NSCLC angiogenesis, progression, or prognosis, ${ }^{7,8}$ there is still no effective predictive or prognostic biomarker clinically used, partly because most patients who are clinically diagnosed are in a middle or advanced stage. Consequently, the 5-year survival rate of NSCLC is as low as approximately $11 \%{ }^{9}$

Fibroblast growth factor receptors (FGFRs) consist of a family of four members, FGFR1, 2, 3, and 4, which have been demonstrated to be involved in the progression 
and prognosis of many kinds of cancers. ${ }^{10}$ They can activate downstream signaling pathways via binding with their ligands, which mostly are FGFs. Interestingly, FGFRs have diverse functions and downstream signaling pathways, which depend on binding different FGF ligands and alternative splicing. In the FGFR family, FGFR4 is distinguished because of its feature of high expression in liver. ${ }^{11}$ FGFR4 overexpression or mutation was demonstrated to be significantly associated with poor prognosis in many kinds of cancers, including hepatocellular carcinoma, prostate, breast, pancreatic, gynecologic gastric cancers, cholangiocarcinoma, and rhabdomyosarcomas. ${ }^{12-15}$ However, the significance of FGFR4 in lung cancer is still not well elucidated.

In our experiments, we detected the expression of FGFR4 in 237 cases of NSCLC with immunohistochemistry (IHC), and analyzed the correlation between FGFR4 and the clinicopathologic features in NSCLC. Furthermore, we identified the independent prognostic value of FGFR4 by univariate and multivariate analysis. After confirmation of FGFR4 as an independent prognostic factor, we performed cell function assays such as proliferation to evaluate the significance of FGFR4 in NSCLC progression.

\section{Materials and methods Patients and follow-up}

Samples of NSCLC were obtained from the Pathological Department of Linyi Hospital and Yishui Central Hospital with prior approval of the patients and the Ethical Committees of these two hospitals. Three hundred and six patients were diagnosed with NSCLC and had undergone pulmonary lobectomy plus regional lymph node dissection from 2003 to 2007, and these patients made up the primary cohort. From the primary cohort, the validation cohort of 237 patients was selected with the following criteria: 1) available follow-up data; 2) available and enough samples; 3) R0 resection. Two senior pathologists confirmed the pathological diagnosis and selected proper sections for IHC. The paper was organized according to the REMARK instruction. Pathologic tumor-node-metastasis (pTNM) classification was based on the 7 th International Union Against Cancer (2009).

\section{IHC and evaluation}

All NSCLC specimens were fixed by $10 \%$ formalin and embedded in paraffin, followed by cutting as serial sections deparaffinized with xylene. Slides were incubated in citrate buffer ( $\mathrm{pH}=6.0$ ) in a microwave oven for 30 minutes to achieve antigen retrieval. After that, specimens were incubated in $3 \% \mathrm{H}_{2} \mathrm{O}_{2}$ in methanol for 20 minutes for endogenous peroxidase enzyme blocking. Primary antibody with dilution at 1:100 was used to incubate the tissue at $4^{\circ} \mathrm{C}$ overnight and then corresponding biotinylated secondary antibody and streptavidin-peroxidase complex was used to incubate at $37^{\circ} \mathrm{C}$ for 30 minutes. Finally, 3,3'-diaminobenzidine solution was used to make staining visible and hematoxylin was used for counterstaining. In the IHC test, the negative control was sampled with phosphate-buffered saline incubation instead of primary antibody, with other procedures all the same, while positive control was hepatocarcinoma sections, which had high FGFR4 expression.

The criterion of IHC evaluation was the combination of staining intensity and positive cell percentage. The percentage scores of immunoreactive cells were defined as follows: 0 for $10 \%$ positive cells; 1 for $10 \%-30 \%$ positive cells; 2 for $30 \%-50 \%$ cells; and 3 for $50 \%$ or more cells. The staining intensity can be described as follows: 0 for negative staining; 1 for weak staining; 2 for moderate staining; and 3 for strong staining. The final IHC score was defined as the multiplication of the staining intensity score and the positive cell score. The criteria for high FGFR4 expression and low FGFR4 expression were arbitrarily defined as $\geq 4$ for high FGFR4 expression and $<4$ for low FGFR4 expression.

\section{Cell culture and reagents}

Two kinds of NSCLC adenocarcinoma cell lines (A549 and H1299) and two squamous carcinoma cell lines (SKMES-1 and H520), as well as HepG2 and HEK293 cells, were purchased from the Institute of Biochemistry and Cell Biology of the Chinese Academy of Sciences (Shanghai, People's Republic of China). A549, H1299, and H520 cells were cultured in RPMI-1640, while SK-MES-1, HepG2, and HEK293 were cultured in Dulbecco's Modified Eagle's Medium (DMEM), supplemented with 10\% fetal bovine serum, $100 \mathrm{U} / \mathrm{mL}$ penicillin, and $100 \mathrm{mg} / \mathrm{mL}$ streptomycin. RPMI-1640, DMEM, penicillin, streptomycin, fetal bovine serum, and trypsin were purchased from Thermo Fisher Scientific (Waltham, MA, USA). Anti-FGFR4 and anti$\beta$-actin primary antibody were obtained from Santa Cruz Biotechnology Inc. (Dallas, TX, USA). 3-(4,5-dimethyl-2thiazolyl)-2,5-diphenyl-2-H-tetrazolium bromide (MTT) kit was from Sangon Company (Shanghai, People's Republic of China).

\section{Immunoblotting}

Immunoblotting was used to detect the protein expression in NSCLC cells. Briefly, cells were lysed with RIPA lysis 
buffer on ice, then scraped and transferred into an Eppendorf tube. After centrifugation at $10,000 \times g$ at $4{ }^{\circ} \mathrm{C}$ for 30 minutes, the supernatant was transferred into another tube and protein concentration was tested by Bradford method, followed by mixing with $2 \times$ loading buffer and boiling for 10 minutes for protein denaturation. After electrophoresis with $10 \mu \mathrm{g}$ total protein, the protein was transferred to a nitrocellulose filter membrane (PALL Corporation) and subsequently blocked with $5 \%$ defatted milk. The nitrocellulose membrane was then incubated in primary antibody diluted in $5 \%$ bovine serum albumin at $4{ }^{\circ} \mathrm{C}$ overnight. The nitrocellulose membrane was finally incubated in corresponding HRP-tagged secondary antibody, and then visualized by addition of ECL reagent (EMD Millipore, Billerica, MA, USA). The semiquantitation of the immunoblotting result was achieved using the software ImageJ (National Institutes of Health [NIH], Bethesda, MD, USA).

\section{FGFR4 knockdown, overexpression, and transfection}

FGFR4 small interfering RNA (Thermo Fisher Scientific) was used for FGFR4 knockdown. The siRNA sequences were designed referring to a previous study. ${ }^{15}$ The sense sequence was 5'-GCCGACACAAGAACAUCAUTT-3', and the antisense sequence was 5'-AugauguUCUUGUGUCGGCTT-3'. As for the scrambled oligonucleotide RNA, the sense sequence was 5'-UUCUCCGAACGUGUCACGUTT-3' and the anti-sense sequence was 5'-ACGUGACACGUUCGGAGAATT-3'.

Plasmid of pFLAG-CMV-2 vector or pFLAG-CMV-2FGFR4 was purchased from Genephama Company (Shanghai, People's Republic of China). Transfection of siRNA or plasmid was accomplished using Lipofectamine 2000 (Thermo Fisher Scientific), according to the transfection manual.

\section{RNA extraction and real-time polymerase chain reaction analysis}

Total RNA was purified from cancer tissue with TRIzol reagent after tissue grind and homogenation. Synthesis of cDNA was synthesized, and quantitative polymerase chain reaction (PCR) was realized by the StepOnePlus real-time PCR system (Thermo Fisher Scientific) using the SYBR Green method according to the manual. GAPDH (glyceraldehyde 3-phosphate dehydrogenase) was applied as an internal control. The sequences of primers used for real-time PCR experiments were designed following previous study and shown below:

- FGFR4 forward: 5'-CTGTGGCCGTCAAGATGCT CAA-3
- FGFR4 reverse: 5'-ATGTTCTTGTGTCGGCCG ATCA-3'

- GAPDH forward: 5'-GGGAAGGTGAAGGTCGGA GTC-3'

- GAPDH reverse: 5'-CCATGGGTGGAATCATATT GGAA-3'.

\section{MTT assay}

MTT assay was used to evaluate cell proliferation. Cells at logarithmic phase were trypsinized and passaged into 96-well plate at a density of 4,000 cells per well. After complete adhesion, cells were starved in serum-free medium and then incubated in normal medium with $10 \%$ fetal bovine serum, from which time was recorded. After incubation in normal medium for 0-72 hours, $10 \mu \mathrm{L}$ MTT was added to the cells at concentration $10 \mathrm{mg} / \mathrm{mL}$, followed by incubation at $37^{\circ} \mathrm{C}$ for 4-6 hours. The supernatant was discarded carefully and the crystals at the bottom were dissolved in $100 \mu \mathrm{L}$ dimethyl sulfoxide. Absorbance at $490 \mathrm{~nm}$ was measured with a microplate reader (Molecular Devices LLC, Sunnyvale, CA, USA). Absorbance at $490 \mathrm{~nm}$ at the 0 time point was set as the baseline and the optical density at $490 \mathrm{~nm}$ of other groups was standardized with the ratio to baseline.

\section{Statistical analysis}

All statistical data were analyzed with SPSS 17.0 software (SPSS Inc., Chicago, IL, USA). The correlation between FGFR4 expression and the clinicopathologic features were analyzed with chi-square test. The univariate analysis was performed with the Kaplan-Meier survival curve method, and statistical differences were compared with a log-rank test. The multivariate analysis was carried out with Cox regression model. In experiments in vitro, the difference of the mean value between different groups was analyzed with Student's $t$-test. $P<0.05$ was considered to be statistically significant.

\section{Results \\ Patient characteristics and FGFR4 expression}

The validation cohort consisted of 237 NSCLC patients. The age of patients ranged from 33 to 78 years old, with median age 60 years (Table 1$)$. Most patients $(65 \%)$ were male in the validation cohort. The clinicopathologic parameters, including tumor size, lymph node metastasis, histological type, differentiation, and smoking, were according to hospital and surgical records. The cohort was divided into FGFR4 highexpression and low-expression groups according to the IHC 
Table I Characteristics of patients

\begin{tabular}{|c|c|c|}
\hline Characteristics & Number & Percentage \\
\hline \multicolumn{3}{|l|}{ Sex } \\
\hline Male & 154 & 65.00 \\
\hline Female & 83 & 35.00 \\
\hline \multicolumn{3}{|l|}{ Age (years) } \\
\hline$<60$ & 95 & 40.10 \\
\hline$\geq 60$ & 142 & 59.90 \\
\hline \multicolumn{3}{|l|}{ Tumor diameter $(\mathrm{cm})$} \\
\hline$\leq 3$ & 72 & 30.40 \\
\hline$>3$ & 165 & 69.60 \\
\hline \multicolumn{3}{|l|}{ Histological subtype } \\
\hline Squamous cell carcinoma & 97 & 40.90 \\
\hline Adenocarcinoma & $|3|$ & 55.30 \\
\hline Others & 9 & 3.80 \\
\hline \multicolumn{3}{|l|}{ Differentiated } \\
\hline Poorly & 111 & 46.80 \\
\hline Moderately & 84 & 35.40 \\
\hline Well & 42 & 17.70 \\
\hline \multicolumn{3}{|l|}{ Lymph node metastasis } \\
\hline No & 124 & 52.30 \\
\hline Yes & 113 & 47.70 \\
\hline \multicolumn{3}{|l|}{ TNM stage } \\
\hline 1 & 114 & 48.10 \\
\hline II & 79 & 33.30 \\
\hline III-IV & 44 & 18.60 \\
\hline \multicolumn{3}{|l|}{ Smoking } \\
\hline No & 95 & 40.10 \\
\hline Yes & 142 & 59.90 \\
\hline \multicolumn{3}{|l|}{ FGFR4 expression } \\
\hline Low & 126 & 53.20 \\
\hline High & 111 & 46.80 \\
\hline
\end{tabular}

Abbreviations: FGFR4, fibroblast growth factor receptor 4; TNM, tumor-nodemetastasis.

criteria described in "Materials and methods". In our study, FGFR4 expression was mainly observed in both cytoplasm and membrane (Figure 1A-D). Statistically, the rate of higher FGFR4 expression was 46.8\% (111/237) in NSCLC. To compare the FGFR4 expression in tumor tissue or adjacent normal tissue, we detected the FGFR4 mRNA level from 12 pairs of frozen samples of NSCLC with quantitative PCR. It turned out that FGFR4 mRNA in tumor tissues was significantly higher than mRNA in normal tissues (Figure 1E).

\section{Correlation between FGFR4 and clinicopathologic factors in NSCLC}

To screen suspicious factors correlated to FGFR4 expression, we analyzed FGFR4 association with clinicopathologic factors in NSCLC with the chi-square method (Table 2). Consequently, we found the FGFR4 higher-expression group had more cases of larger tumor diameter $(P=0.039)$, indicating that FGFR4 may play important role in NSCLC cell proliferation. However, no other significant correlations between FGFR4 and other factors were observed in our experiments except the tumor diameter.

\section{Prognostic value of FGFR4 in NSCLC}

To evaluate the prognostic value of FGFR4 in NSCLC, we first analyzed the correlation between FGFR4 expression and the 5-year overall survival rate with univariate analysis (Table 3). With the Kaplan-Meier method, we demonstrated that FGFR4 higher expression was correlated to poorer prognosis in NSCLC $(P=0.009)$. In the FGFR4 higher-expression group, the 5 -year overall survival rate was $17.4 \%$ with average survival time 39.8 months, while in the lower-expression group, the 5 -year overall survival rate was $54.8 \%$ with average survival time 62.1 months (Figure 2A). In addition, stage of lymph node metastasis was also defined as a prognostic factor in NSCLC $(P=0.003)$. Positive lymphatic invasion had a poorer prognosis than negative lymphatic invasion $(42.7 \%$ vs $52.7 \%$ survival rate) (Figure $2 \mathrm{~B}$ ).

Moreover, we further performed multivariate analysis with Cox regression model to detect whether FGFR4 was an independent prognostic factor in NSCLC (Table 4). Almost all clinicopathologic features were collected into the model, including sex, age, tumor size, differentiation, lymph node metastasis, smoking, and FGFR4 expression. With multivariate analysis, we confirmed FGFR4 as an independent prognostic factor $(P=0.002)$, with $95 \%$ confidence interval 1.35-3.71 and hazard ratio 2.24. Additionally, stage of lymph node invasion was also defined as an independent prognostic factor $(P=0.001)$, with $95 \%$ confidence interval $1.38-3.79$ and hazard ratio 2.23. No other clinicopathological parameter was identified as an independent prognostic factor in the Cox regression model in NSCLC.

\section{FGFR4 promotes NSCLC cell line proliferation}

We demonstrated that FGFR4 expression was correlated with tumor diameter from analyzing clinical data with chi-square test, which indicated that FGFR4 may play an essential role in NSCLC proliferation. To confirm the result from clinical study with experiments in vitro, we performed MTT assay to evaluate the FGFR4 value in NSCLC cell line proliferation. We first detected FGFR4 expression in NSCLC cell lines to select proper cell models for FGFR4 regulation (Figure 3A). Four NSCLC cell lines were collected and used for FGFR4 detection, including adenocarcinoma cell lines A549 and H1299 and two squamous carcinomas cell lines, SK-MES-1 


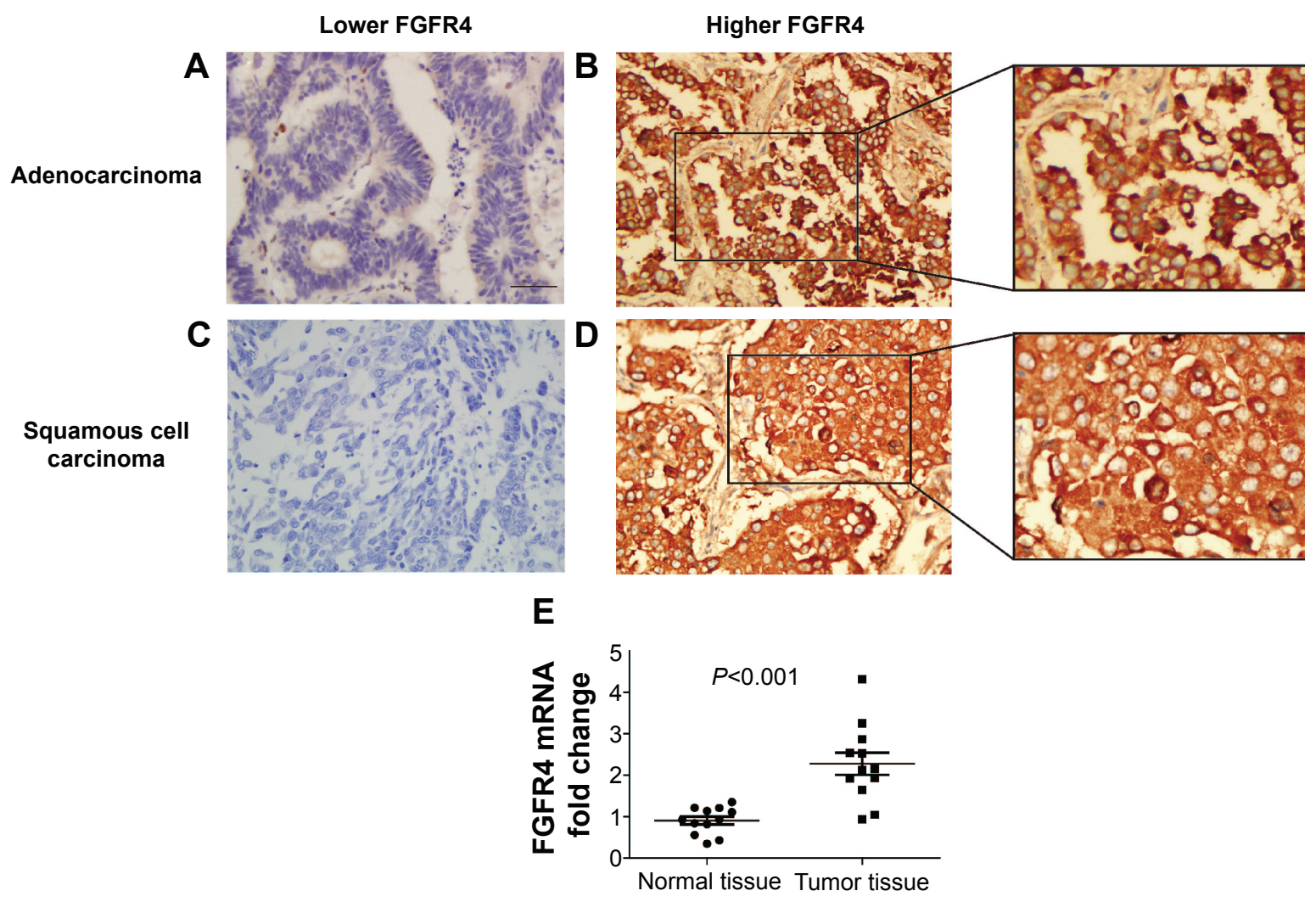

Figure I FGFR4 expression in non-small-cell lung cancer.

Notes: (A) Lower FGFR4 expression in lung adenocarcinoma. (B) Higher FGFR4 expression in lung adenocarcinoma. (C) Lower FGFR4 expression in squamous cell carcinoma. (D) Higher FGFR4 expression in squamous cell carcinoma. Scale bar: $50 \mu \mathrm{m}$. (E) FGFR4 mRNA level in tumor tissue and adjacent normal tissue ( $\mathrm{n}=12$ ). Abbreviation: FGFR4, fibroblast growth factor receptor 4.

and H520, with HEK293 cells as negative control and HepG2 cells as positive control, which had high levels of FGFR4 expression. Among all the four cell lines, SK-MES-1 and H520 had similar FGFR4 expression, while A549 had the highest and H1299 had the lowest FGFR4 expression (Figure 3B). Moreover, we used MTT assay to access the regulation of FGFR4 in NSCLC proliferation. SK-MES-1 and A549 cells were transfected by scrambled RNA or siRNA to achieve FGFR4 knockdown and transfected by FLAGFGFR4 or control p-FLAG-CMV2 to accomplish FGFR4 overexpression. After successful transfection, cells were starved overnight and then continued to be cultured in normal medium for 48 or 72 hours. The optical density of the control group at $490 \mathrm{~nm}$ was set as the baseline and optical density at $490 \mathrm{~nm}$ of other groups was measured by ratio with baseline. In both SK-MES-1 (Figure 3C) and A549 (Figure 3D), the overexpression of FGFR 4 can enhance the proliferation, and the knockdown of FGFR4 can reduce the proliferation, which demonstrated that FGFR4 plays an important role in NSCLC and explains why the high-FGFR4 group had more cases of tumor diameter larger than $3 \mathrm{~cm}$ in the chi-square test.

\section{Discussion}

In our study, we systemically investigated the expression of FGFR4 in 237 cases of NSCLC for the first time and found that FGFR4 was associated with tumor diameter by chi-square test. With univariate and multivariate analysis, we identified FGFR4 as an independent prognostic factor of NSCLC. Furthermore, we proved that FGFR4 can promote NSCLC cell line proliferation, indicating that FGFR4 could be a potential molecular drug target of NSCLC chemotherapy.

In NSCLC, the FGFR family has been proved to be significantly associated with NSCLC progression. Amplification of FGFR1 can lead to poorer prognosis in early NSCLC, ${ }^{16}$ and several FGFR1 inhibitors have been demonstrated to suppress the growth of NSCLC cells overexpressing FGFR1 in NSCLC xenograft models. ${ }^{17,18}$ These inhibitors are mostly small-molecular inhibitors such as AZD4547, ponatinib (AP24534), and nintedanib (BIBF 1120). As a distinguishing feature, FGFR1/3 gene fusions are reported to define a molecular subset of NSCLC with distinct clinical characteristics. ${ }^{19}$ This kind of FGFR diversity and redundancy 
Table 2 Correlation between FGFR4 and clinicopathologic parameters

\begin{tabular}{|c|c|c|c|c|}
\hline \multirow[t]{2}{*}{ Characteristics } & \multicolumn{4}{|c|}{ FGFR4 expression } \\
\hline & Number & Low & High & P* \\
\hline \multicolumn{5}{|l|}{ Sex } \\
\hline Male & 154 & 83 & 71 & 0.759 \\
\hline Female & 83 & 43 & 40 & \\
\hline \multicolumn{5}{|l|}{ Age (years) } \\
\hline$<60$ & 95 & 56 & 39 & 0.144 \\
\hline$\geq 60$ & 142 & 70 & 72 & \\
\hline \multicolumn{5}{|l|}{ Tumor diameter $(\mathrm{cm})$} \\
\hline$\leq 3$ & 72 & 41 & 31 & 0.039 \\
\hline$>3$ & 165 & 70 & 95 & \\
\hline \multicolumn{5}{|l|}{ Histological subtype } \\
\hline Squamous cell carcinoma & 97 & 54 & 43 & 0.429 \\
\hline Adenocarcinoma & $|3|$ & 69 & 62 & \\
\hline Others & 9 & 3 & 6 & \\
\hline \multicolumn{5}{|l|}{ Differentiated } \\
\hline Poorly & 111 & 57 & 54 & 0.811 \\
\hline Moderately & 84 & 45 & 39 & \\
\hline Well & 42 & 24 & 18 & \\
\hline \multicolumn{5}{|l|}{ Lymph node metastasis } \\
\hline No & 124 & 69 & 55 & 0.348 \\
\hline Yes & 113 & 56 & 57 & \\
\hline \multicolumn{5}{|l|}{ TNM stage } \\
\hline I & 114 & 53 & 61 & 0.662 \\
\hline II & 79 & 32 & 47 & \\
\hline III-IV & 44 & 18 & 26 & \\
\hline \multicolumn{5}{|l|}{ Smoking } \\
\hline No & 95 & 55 & 40 & 0.232 \\
\hline Yes & 142 & 71 & 71 & \\
\hline
\end{tabular}

Note: *Chi-square test.

Abbreviations: FGFR4, fibroblast growth factor receptor 4; TNM, tumor-nodemetastasis.

enormously increases the complexity and possibility of FGFR signaling pathway and the outcome it regulates.

FGFR4 is attracting more and more attention as a potential oncogene. FGFR4 gene amplification or protein overexpression is observed in several kinds of cancers. Different
Table 3 Univariate analysis of non-small-cell lung cancer

\begin{tabular}{|c|c|c|c|}
\hline Characteristics & $\begin{array}{l}\text { Survival time } \\
\text { (months) }\end{array}$ & $\begin{array}{l}\text { 5-year } \\
\text { survival rate }\end{array}$ & $P^{*}$ \\
\hline \multicolumn{4}{|l|}{ Sex } \\
\hline Male & 55.8 & 46.8 & 0.309 \\
\hline Female & 52.8 & 46.6 & \\
\hline \multicolumn{4}{|l|}{ Age (years) } \\
\hline$<60$ & 56.3 & 42.5 & 0.646 \\
\hline$\geq 60$ & 54.3 & 49.6 & \\
\hline \multicolumn{4}{|c|}{ Tumor diameter $(\mathrm{cm})$} \\
\hline$\leq 3$ & 53.1 & 36.1 & 0.510 \\
\hline$>3$ & 58.7 & 54.8 & \\
\hline \multicolumn{4}{|l|}{ Differentiated } \\
\hline Poorly & 52.5 & 39.9 & 0.942 \\
\hline Moderately & 57.8 & 53.1 & \\
\hline Well & 54.0 & 47.3 & \\
\hline \multicolumn{4}{|c|}{ Lymph node metastasis } \\
\hline No & 60.7 & 50.7 & 0.003 \\
\hline Yes & 50.9 & 42.7 & \\
\hline \multicolumn{4}{|l|}{ TNM stage } \\
\hline I & 56.2 & 50.2 & 0.013 \\
\hline II & 50.2 & 45.3 & \\
\hline III-IV & 44.6 & 35.6 & \\
\hline \multicolumn{4}{|l|}{ Smoking } \\
\hline No & 54.8 & 48.8 & 0.612 \\
\hline Yes & 57.0 & 44.8 & \\
\hline \multicolumn{4}{|l|}{ FGFR4 expression } \\
\hline Low & 62.1 & 54.8 & 0.009 \\
\hline High & 39.8 & 17.4 & \\
\hline
\end{tabular}

Note: *Log-rank test.

Abbreviations: FGFR4, fibroblast growth factor receptor 4; TNM, tumor-nodemetastasis.

from FGFR1, the function and role of FGFR4 in NSCLC has not been well elucidated. Our study is the first research on FGFR4 effects on prognosis of NSCLC. We hope this study can trigger more interest in FGFR function and targeted therapy in NSCLC. Unfortunately, this research focused on clinical study of the correlation between FGFR4 and NSCLC prognosis, and did not determine the underlying molecular
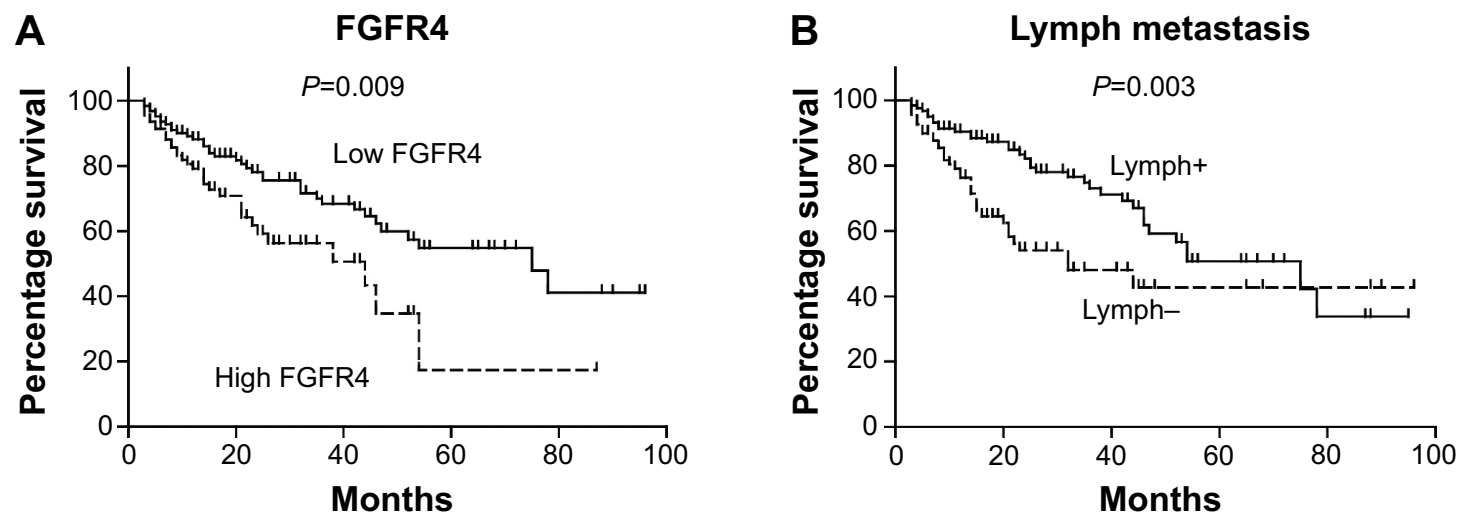

Figure 2 Correlations between overall survival rate and FGFR4 expression and lymph invasion status.

Notes: Higher FGFR4 expression (A) and positive lymphatic invasion (B) can predict unfavorable prognosis of serous ovarian cancer.

Abbreviation: FGFR4, fibroblast growth factor receptor 4. 
Table 4 Multivariate analysis of non-small-cell lung cancer

\begin{tabular}{|c|c|c|c|}
\hline Characteristics & HR & $95 \% \mathrm{Cl}$ & P* \\
\hline \multicolumn{4}{|l|}{ Sex } \\
\hline Male & 1 & & \\
\hline Female & 1.41 & $0.83-2.32$ & 0.182 \\
\hline \multicolumn{4}{|l|}{ Age (years) } \\
\hline$<60$ & 1 & & \\
\hline$\geq 60$ & I.I & $0.66-1.83$ & 0.73 \\
\hline \multicolumn{4}{|c|}{ Tumor diameter $(\mathrm{cm})$} \\
\hline$\leq 3$ & 1 & & \\
\hline$>3$ & 1.28 & $0.78-2.08$ & 0.33 \\
\hline \multicolumn{4}{|l|}{ Differentiated } \\
\hline Well & 1 & & \\
\hline Moderately & 0.64 & $0.21-1.13$ & 0.22 \\
\hline Poorly & 0.7 & $0.33-1.46$ & 0.34 \\
\hline \multicolumn{4}{|c|}{ Lymphatic metastasis } \\
\hline No & I & & \\
\hline Yes & 2.23 & $1.38-3.79$ & 0.001 \\
\hline \multicolumn{4}{|l|}{ Smoking } \\
\hline No & I & & \\
\hline Yes & 1.13 & $0.69-1.82$ & 0.636 \\
\hline \multicolumn{4}{|l|}{ FGFR4 expression } \\
\hline Low & I & & \\
\hline High & 2.24 & $1.35-3.7 \mid$ & 0.002 \\
\hline
\end{tabular}

Note: *Cox proportional hazards regression.

Abbreviations: $\mathrm{Cl}$, confidence interval; FGFR4, fibroblast growth factor receptor 4; $H R$, hazard ratio.

mechanism. More experiments are needed to elucidate downstream signaling pathways initiated by FGFR 4 as well as the entire signaling network of FGFR4. In addition, the animal model is an essential tool for studying the role of biomarkers in cancer progression. We hope that our results in vitro can trigger further investigation of the role of FGFR4 in IHCC in vivo. Moreover, an important feature of FGFR4 is its polymorphism at the 388 site. Previous study indicates that the single nucleotide polymorphism of Arg388 is associated with prognosis in Japanese patients with NSCLC. ${ }^{20}$ Similar study of Arg388 allele function in the People's Republic of China or other regions is also worthy of further experiments. The FGFR4 role in NSCLC in mouse models is not well known. Chemotherapy is an essential treatment for NSCLC, including preoperational chemotherapy and postoperational adjuvant chemotherapy. Currently used targeted chemical drugs are usually targeted at EGFR (gefitinib, erlotinib, or cetuximab) and VEGF (bevacizumab, ZD6474, or cediranib). Since the FGFR1 oncogenic role in NSCLC has been gradually revealed in recent years, chemical drugs targeting FGFR1 are more and more intriguing, and several FGFR1 inhibitors are in clinical trial. Our finding that FGFR4 is correlated to poor prognosis may bring new insight into NSCLC chemotherapeutic treatment.

\section{Conclusion}

We find that FGFR4 expression is significantly associated with tumor size and prognosis, and we identify FGFR4 as an independent prognostic factor in NSCLC. Moreover, FGFR4 can promote NSCLC cell proliferation in vitro. We hope our study can help with finding new chemotherapeutic drugs
A

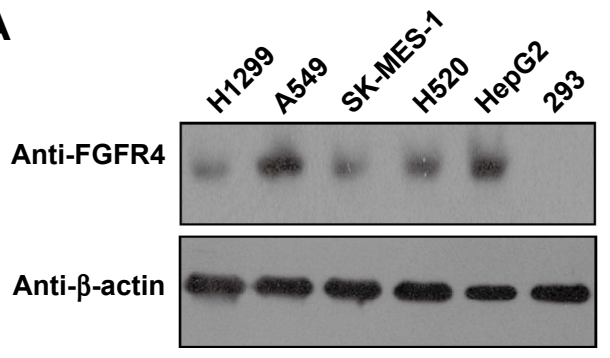

C

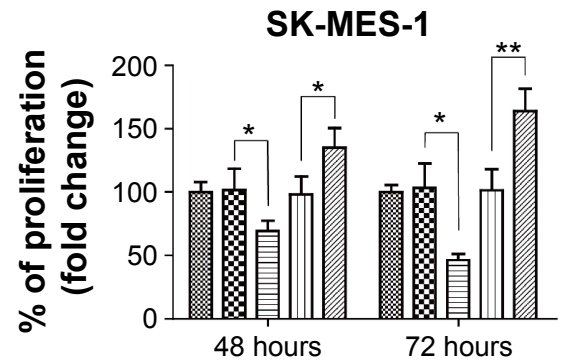

B

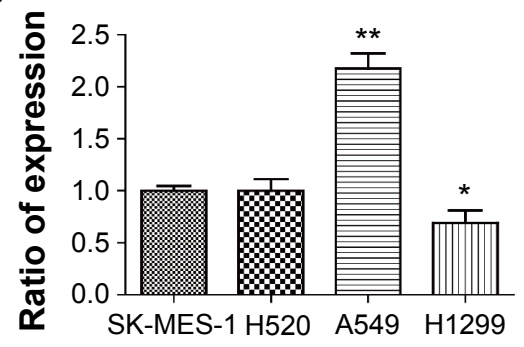

D

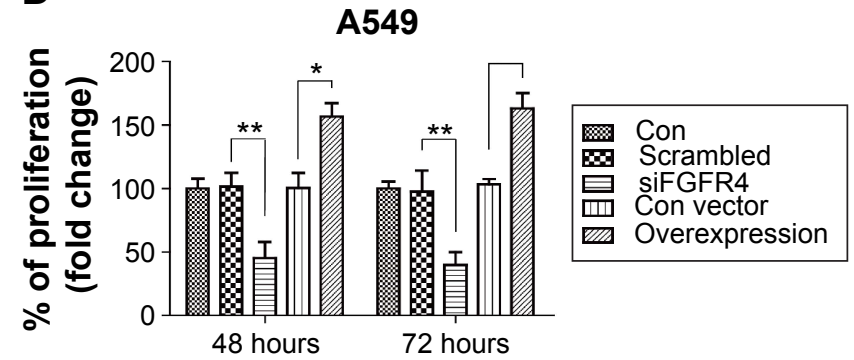

Figure 3 Role of FGFR4 in non-small-cell lung cancer cell line proliferation.

Notes: (A) FGFR4 expression in adenocarcinoma cell lines A549 and HI299 and squamous carcinomas cell lines SK-MES-I and H520, with hepatocellular carcinoma HepG2 cells as positive control and HEK 293 cells as negative control. (B) Semi-quantitative analysis of signals from (A) using Imagej software. (C and D) With FGFR4 knockdown or overexpression, FGFR4 was proved to be able to promote cell proliferation in cell line SK-MES-I (C) or A549 (D). $* P<0.05 ; * P<0.01$.

Abbreviation: FGFR4, fibroblast growth factor receptor 4. 
and increase the survival time and quality of life for patients with NSCLC.

\section{Disclosure}

The authors report no conflicts of interest in this work.

\section{References}

1. Jett JR, Cortese DA, Fontana RS. Lung cancer: current concepts and prospects. CA Cancer J Clin. 1983;33:74-86.

2. Lu M, Tian $\mathrm{H}$, Yue $\mathrm{W}$, et al. TFIIB-related factor 2 over expression is a prognosis marker for early-stage non-small cell lung cancer correlated with tumor angiogenesis. PLoS One. 2014;9:e88032.

3. Herbst RS, Heymach JV, Lippman SM. Lung cancer. $N$ Engl J Med. 2008;359:1367-1380.

4. Goldstraw P, Ball D, Jett JR, et al. Non-small-cell lung cancer. Lancet. 2011;378:1727-1740

5. Tang H, Tian H, Yue W, et al. Overexpression of LAPTM4B is correlated with tumor angiogenesis and poor prognosis in non-small cell lung cancer. Med Oncol. 2014;31:974.

6. Li T, Kung HJ, Mack PC, Gandara DR. Genotyping and genomic profiling of non-small-cell lung cancer: implications for current and future therapies. J Clin Oncol. 2013;31:1039-1049.

7. Rosell R, Bivona TG, Karachaliou N. Genetics and biomarkers in personalisation of lung cancer treatment. Lancet. 2013;382:720-731.

8. Carlini MJ, Roitman P, Nuñez M, et al. Clinical relevance of galectin-1 expression in non-small cell lung cancer patients. Lung Cancer. 2014; 84:73-78.

9. Verdecchia A, Francisci S, Brenner H, et al; EUROCARE-4 Working Group. Recent cancer survival in Europe: a 2000-2002 period analysis of EUROCARE-4 data. Lancet Oncol. 2007;8:784-796.

10. Kelleher FC, O'Sullivan H, Smyth E, McDermott R, Viterbo A. Fibroblast growth factor receptors, developmental corruption and malignant disease. Carcinogenesis. 2013;34:2198-2205.
11. Song KH, Li T, Owsley E, Strom S, Chiang JY. Bile acids activate fibroblast growth factor 19 signaling in human hepatocytes to inhibit cholesterol 7alpha-hydroxylase gene expression. Hepatology. 2009;49: 297-305.

12. Ye YW, Zhou Y, Yuan L, et al. Fibroblast growth factor receptor 4 regulates proliferation and antiapoptosis during gastric cancer progression. Cancer. 2011;117:5304-5313.

13. Sugiyama N, Varjosalo M, Meller P, et al. Fibroblast growth factor receptor 4 regulates tumor invasion by coupling fibroblast growth factor signaling to extracellular matrix degradation. Cancer Res. 2010; 70:7851-7861.

14. Taylor JG 6th, Cheuk AT, Tsang PS, et al. Identification of FGFR4-activating mutations in human rhabdomyosarcomas that promote metastasis in xenotransplanted models. J Clin Invest. 2009;119: 3395-3407.

15. Xu YF, Yang XQ, Lu XF, et al. Fibroblast growth factor receptor 4 promotes progression and correlates to poor prognosis in cholangiocarcinoma. Biochem Biophys Res Commun. 2014;446:54-60.

16. Cihoric N, Savic S, Schneider S, et al. Prognostic role of FGFR1 amplification in early-stage non-small cell lung cancer. Br J Cancer. 2014; 110:2914-2922.

17. Zhang J, Zhang L, Su X, et al. Translating the therapeutic potential of AZD4547 in FGFR1-amplified non-small cell lung cancer through the use of patient-derived tumor xenograft models. Clin Cancer Res. 2012;18:6658-6667.

18. Ren M, Hong M, Liu G, et al. Novel FGFR inhibitor ponatinib suppresses the growth of non-small cell lung cancer cells overexpressing FGFR1. Oncol Rep. 2013;29:2181-2190.

19. Wang R, Wang L, Li Y, et al. FGFR1/3 tyrosine kinase fusions define a unique molecular subtype of non-small cell lung cancer. Clin Cancer Res. 2014;20:4107-4114.

20. Sasaki H, Okuda K, Kawano O, Yukiue H, Yano M, Fujii Y. Fibroblast growth factor receptor 4 mutation and polymorphism in Japanese lung cancer. Oncol Rep. 2008;20:1125-1130.
OncoTargets and Therapy

\section{Publish your work in this journal}

OncoTargets and Therapy is an international, peer-reviewed, open access journal focusing on the pathological basis of all cancers, potential targets for therapy and treatment protocols employed to improve the management of cancer patients. The journal also focuses on the impact of management programs and new therapeutic agents and protocols on

\section{Dovepress}

patient perspectives such as quality of life, adherence and satisfaction The manuscript management system is completely online and includes a very quick and fair peer-review system, which is all easy to use. Visit http://www.dovepress.com/testimonials.php to read real quotes from published authors. 